\title{
Effect of hospital volume on outcomes of total hip arthroplasty: a systematic review and meta-analysis
}

Syed Hamza Mufarrih ${ }^{1 *}$ (D, Muhammad Owais Abdul Ghani ${ }^{2}$, Russell Seth Martins ${ }^{3}$, Nada Qaisar Qureshi ${ }^{4}$, Sayyeda Aleena Mufarrih ${ }^{5}$, Azeem Tariq Malik ${ }^{6}$ and Shahryar Noordin ${ }^{7}$

\begin{abstract}
Background: A shift in the healthcare system towards the centralization of common yet costly surgeries, such as total hip arthroplasty (THA), to high-volume centers of excellence, is an attempt to control the economic burden while simultaneously enhancing patient outcomes. The "volume-outcome" relationship suggests that hospitals performing more treatment of a given type exhibit better outcomes than hospitals performing fewer. This theory has surfaced as an important factor in determining patient outcomes following THA. We performed a systematic review with meta-analyses to review the available evidence on the impact of hospital volume on outcomes of THA.

Materials and methods: We conducted a review of PubMed (MEDLINE), OVID MEDLINE, Google Scholar, and Cochrane library of studies reporting the impact of hospital volume on THA. The studies were evaluated as per the inclusion and exclusion criteria. A total of 44 studies were included in the review. We accessed pooled data using random-effect meta-analysis.
\end{abstract}

Results: Results of the meta-analyses show that low-volume hospitals were associated with a higher rate of surgical site infections $(1.25[1.01,1.55])$, longer length of stay (RR, $0.83[0.48-1.18])$, increased cost of surgery $(3.44,[2.57$, 4.30]), 90-day complications (RR, 1.80[1.50-2.17]) and 30-day (RR, 2.33[1.27-4.28]), 90-day (RR, 1.26[1.05-1.51]), and 1year mortality rates (RR, 2.26[1.32-3.88]) when compared to high-volume hospitals following THA. Except for two prospective studies, all were retrospective observational studies.

Conclusions: These findings demonstrate superior outcomes following THA in high-volume hospitals. Together with the reduced cost of the surgical procedure, fewer complications may contribute to saving considerable opportunity costs annually. However, a need to define objective volume-thresholds with stronger evidence would be required.

Trial registration: PROSPERO CRD42019123776.

Keywords: Total hip arthroplasty, Hospital volume, THA, Low-volume hospitals vs. high-volume hospitals, THA outcomes, Total hip replacement

\footnotetext{
* Correspondence: hamzamufarrih@live.com

'Department of Biological and Biomedical Sciences, Aga Khan University,

Karachi, Pakistan

Full list of author information is available at the end of the article
}

(C) The Author(s). 2019 Open Access This article is distributed under the terms of the Creative Commons Attribution 4.0 International License (http://creativecommons.org/licenses/by/4.0/), which permits unrestricted use, distribution, and reproduction in any medium, provided you give appropriate credit to the original author(s) and the source, provide a link to the Creative Commons license, and indicate if changes were made. The Creative Commons Public Domain Dedication waiver (http://creativecommons.org/publicdomain/zero/1.0/) applies to the data made available in this article, unless otherwise stated. 


\section{Background}

Total hip arthroplasty (THA), a remarkably successful, safe, and cost-effective treatment for pain and joint dysfunction resulting from end-stage arthritis [1-4], is performed annually for approximately one million patients worldwide, with over 300,000 patients in the USA [5]. These numbers are expected to rise $174 \%$ by 2030 , primarily driven by aging populations and an increase in life expectancy [5]. Although arthroplasty has shown promising results in reducing pain severity and improving the joint function of the patients, there is still room for improvement in terms of shortening length of hospital stay (LOS) and decreasing risk of postoperative dislocation, peri-prosthetic fracture, and infection to effectively lower the overall cost of hip arthroplasty and revision rates.

Since the inception of modern THA in 1960 [6], various studies have identified several factors that may affect the outcomes of the surgery. These include patient-related factors such as age $[7,8]$, gender $[9,10]$, elevated body mass index [11], number of comorbid conditions [12, 13], American Society of Anesthesiologist (ASA) grade [14], neuropsychiatric disorders $[15,16]$, and technical-factors such as surgical complexity, implant type, head size, and bearing surfaces [17-20].

Recently, the concept of hospital factors has surfaced. It has been shown that hospitals performing more treatments of a given type exhibit better outcomes than hospitals performing fewer. This is called the "volume-outcome" relationship and several studies have observed this effect in total hip arthroplasty, where the outcomes of hip arthroplasty in hospitals which perform a higher number of hip arthroplasty procedures annually are better than hospitals which perform a fewer number [21-23]. As the current healthcare system endeavors to implement value, centralization of common yet costly surgeries, such as THAs, to high-volume centers of excellence may be an effective way to control the economic burden. While several studies have investigated the hospital volume relationship, no systematic review or meta-analysis has been conducted to pool the results. In our study, we combine data from all published studies to study the differences in outcomes of hip arthroplasty in high-volume and low-volume hospitals.

\section{Methods}

The review follows the PRISMA guidelines [24].

\section{Search strategy}

A review of PubMed (MEDLINE), OVID MEDLINE, Google Scholar, and Cochrane library review was conducted for studies reporting the effect of hospital volume on outcomes of total hip arthroplasty (THA), since 1980 to March 2019. In order to yield maximum results, the keywords used were ("hospital volume" OR ("hospital" AND "volume") AND ("total hip arthroplasty" OR "THA" OR "total hip replacement" OR "hip replacement"). Duplicates were removed and titles of all studies were screened as per the eligibility criteria. Any ambiguity was resolved through screening the abstract. The full text of articles that met the inclusion criteria was reviewed. The references of the selected studies were screened for potentially relevant studies.

\section{Selection criteria}

Studies reporting the effect of hospital volume on total hip arthroplasty, published in English, with available full texts, were selected. The inclusion criteria and the exclusion criteria have been summarized in Table 1. Two authors (SHM and ATM) independently screened all abstracts from the initial search to assess eligibility for inclusion.

\section{Data extraction}

Data extraction was done by two authors (MAOG and RSM) independently using Excel 2011 software. Data extraction variables were pretested using five papers. The extracted parameters included author name, study design, study duration, number of hips included, reported outcomes, mean age of study population, adjustment for covariates, and percentage of patients lost to follow-up. In addition to this, the cut-off for categorizing hospital volume as high or low, reported complications, the OR/ $\mathrm{RR}$ or HR values along with their confidence interval and $p$ value were also extracted.

The number of patients in low-volume hospital (LVH) and high-volume hospital $(\mathrm{HVH})$ groups and complications (e.g., mortality, surgical site infection) were extracted for the meta-analysis from each study. In case, raw data in terms of crude numbers was not reported, efforts were made to contact the author via email to request them to provide us with the data necessary for the inclusion of their study in the pooled analysis.

Table 1 Eligibility Criteria for studies included in the review

\begin{tabular}{|c|c|}
\hline Inclusion criteria & Exclusion criteria \\
\hline $\begin{array}{l}\text { 1) Studies that compared the outcomes of low-volume hospitals (LVH) and high-volume hospitals }(\mathrm{HVH}) \\
\text { for hip arthroplasty. } \\
\text { 2) Articles in which the study population was undergoing primary or revision THA.* } \\
\text { 3) Reported outcomes included perioperative morbidity/complication, in-hospital mortality, postoperative } \\
\text { mortality within } 1 \text { year, readmission, length of stay (LOS), and cost of surgery. }\end{array}$ & $\begin{array}{l}\text { 1) Less than } 25 \text { cases } \\
\text { 2) Greater than } 10 \% \text { patients lost to } \\
\text { follow-up } \\
\text { 3) Measured outcomes not reporting } \\
\text { significance of results } \\
\text { 4) Studies not available in English }\end{array}$ \\
\hline
\end{tabular}

*Studies reporting relationships between hospital volume and hip arthroplasty following trauma/malignancy were excluded. 


\section{Synthesis of results}

The meta-analysis was performed using RevMan Version 5.3 (The Cochrane Collaboration, Copenhagen, Denmark) for calculating pooled summaries and generating forest plots. Meta-analysis was only possible if the retrieval of sufficient data from the study or through contact with the author had been successful.

There was considerable heterogeneity among the studies in the cutoffs for categorizing hospital volume as low or high. To account for this, and other variations including the fact that studies were performed in different regions of the world, with differences in age groups and technical surgical protocols, we decided to use the Mantel-Haenszel random-effect model to report the risk-ratio and heterogeneity $\left(I^{2}\right)$ in our analysis.

The random effect model assumes that the effect size is obtained from a population of effect sizes. Therefore, the effect size is derived from the sampling of an effect size at random, in addition to measurement error (the inverse function of the sample size). Because the random-effects model considers the two sources of error in effect size, they are able to yield a larger error term and less statistical power than fixed-effect models. However, one could benefit from random effect models over fixed-effect models because of its ability to generalize the result to a broader universe of studies. These models specifically account for the heterogeneity of studies through a statistical parameter representing the inter-study variation. For the parameters recorded in our review, the random-effect model was preferred for the pooling of the data in the meta-analysis.

For pooling means, we used the standard mean difference (SMD) instead of mean difference, so that we could standardize the results of all studies to a uniform scale. This was necessary as the mean values varied widely from region to region (For example, the mean length of stay in studies from Japan ranged between 25-60 days postoperatively while the mean length of stay in studies in the USA ranged between 4-10 days).

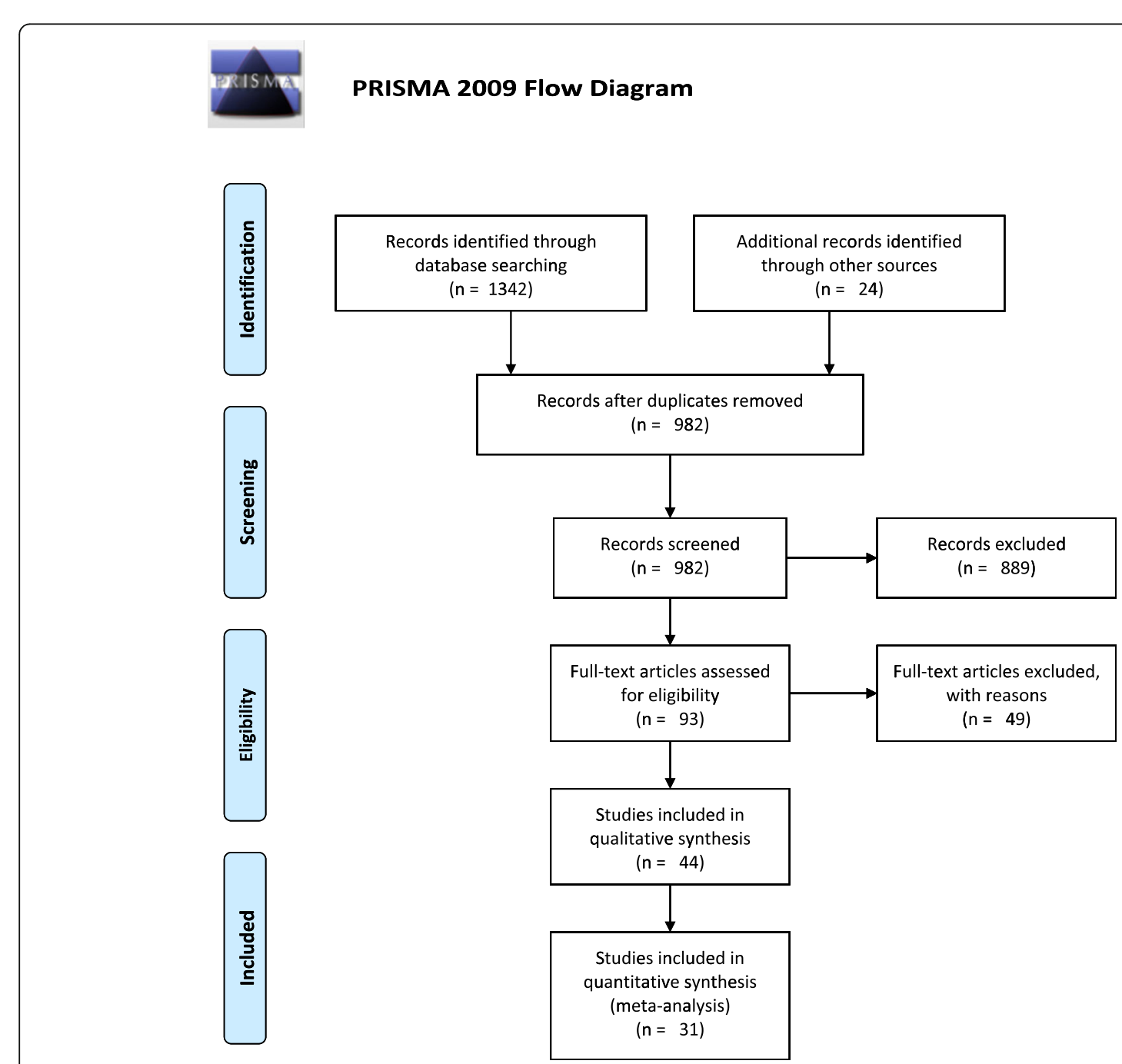

Fig. 1 PRISMA flow diagram for study selection 
The use of standard mean difference expresses the size of the intervention effect in each study relative to the variability observed in the study, rather than comparing it with other studies. Therefore, the net effect determined is the pooled summary of the standard mean difference among each individual study, rather than a comparison with the means of other studies. This was used to compare the difference in length of stay and cost of surgery between $\mathrm{HVH}$ and LVH. The length of stay was reported by many studies in different parts of the world, and the protocols they use for their surgeries vary vastly. Similarly, the cost of the surgeries was reported using different currencies at different times. Such a model is useful to pool studies with such vast heterogeneity.

We decided to pool surgical site infections as per the CDC definition of surgical site infection, 1999 [25].

\section{Quality appraisal of studies}

We used the Grading of Recommendations Assessment, Development and Evaluation (GRADE) system to evaluate the quality of studies in our review [26].

\section{Results}

This work has been reported in accordance with the PRISMA (Preferred Reporting Items for Systematic Reviews and Meta-Analyses) [27] and AMSTAR (Assessing the methodological quality of systematic reviews) Guidelines [28].

\section{Study selection}

A preliminary total of 1342 studies were identified from Google Scholar, PubMed, and Cochrane library. The removal of duplicates yielded 982 studies. Through screening of titles and abstracts, 93 studies which fulfilled the inclusion criteria were extracted. Following full-length reviews, 49 studies were excluded based on the exclusion criteria. Forty-four studies were included in the qualitative review, and only 31 were included in the meta-analysis. The process of study selection has been summarized in the PRISMA flow diagram (Fig. 1: PRISMA flow diagram for study selection).

\section{Study characteristics}

A total of 44 studies were included in the review. Fortytwo studies were retrospective studies where longitudinal data was collected over a certain period of time from pre-existing databases, while 2 were prospective. Six studies had included both primary THA and revision THA [23, 29-33]. The remaining 38 studies were focused solely on primary THA. Data from revision surgeries is described in Additional file 4. Only data from primary THA was used to pool results in our analyses. Twenty-four of the 44 studies were conducted in the USA while the remaining were contributed by 11 unique countries (details in Additional file 1). The average age of the patient population was 67.7 years (reported by 28 studies). Overall, $43.3 \%$ of the patients were male and $56.7 \%$ of the patients were female (reported by 34 studies). Details of the study characteristics are summarized in Additional file 1. A total of 38 studies had adjusted for covariates (details in Additional file 2). Patient comorbid conditions including diabetes mellitus, obesity, dyslipidemia, chronic kidney disease, heart disease, hypothyroidism, chronic obstructive pulmonary disease, peripheral vessel disease, and depression were only reported by 13 studies (details in Additional file 5).

\section{Outcomes and findings}

These studies include data from 1988 to 2011. Detailed results of data extraction on reported outcomes are presented in Additional file 3.

\section{Surgical-site infections}

A total of 8 studies [31, 34-40] totaling 200,950 hip arthroplasties were pooled to compare the rates of

\begin{tabular}{|c|c|c|c|c|c|c|c|c|c|c|}
\hline Study or Subgroup & \multicolumn{2}{|c|}{ LVH } & \multicolumn{2}{|c|}{ HVH } & Weight & \multicolumn{2}{|l|}{ Risk Ratio } & \multicolumn{2}{|c|}{$\begin{array}{cl}\text { Risk Ratio } \\
\text { M-H, Random, } 95 \% \mathrm{Cl}\end{array}$} & \\
\hline Boas 2015 & 191 & 15170 & 362 & 40764 & $22.1 \%$ & $1.42[1.19,1.69]$ & & & $\rightarrow$ & \\
\hline Katz 2001 & 68 & 20638 & 35 & 20523 & $13.3 \%$ & $1.93[1.29,2.90]$ & & & $\longrightarrow$ & \\
\hline Kreder 1997 & 4 & 476 & 38 & 4793 & $3.7 \%$ & $1.06[0.38,2.96]$ & & & & \\
\hline Kreder 1998 & 5 & 474 & 14 & 1700 & $3.8 \%$ & $1.28[0.46,3.54]$ & & & & \\
\hline Meyer 2011 & 43 & 3884 & 440 & 52383 & $16.7 \%$ & $1.32[0.97,1.80]$ & & & -- & \\
\hline Muilwijk 2007 & 106 & 2614 & 228 & 8038 & $20.0 \%$ & $1.43[1.14,1.79]$ & & & $\rightarrow$ & \\
\hline Namba 2012 & 42 & 8799 & 58 & 10610 & $13.7 \%$ & $0.87[0.59,1.30]$ & & $\longrightarrow$ & & \\
\hline Paterson 2010 & 12 & 5303 & 23 & 4781 & $6.9 \%$ & $0.47[0.23,0.94]$ & & & & \\
\hline Total $(95 \% \mathrm{Cl})$ & & 57358 & & 143592 & $100.0 \%$ & $1.25[1.01,1.55]$ & & & & \\
\hline Total events & 471 & & 1198 & & & & & & & \\
\hline $\begin{array}{l}\text { Heterogeneity: } \mathrm{Tau}^{2} \\
\text { Test for overall effect }\end{array}$ & $\begin{array}{l}0.05 ; \mathrm{Ch} \\
\mathrm{Z}=2.06\end{array}$ & $\begin{array}{l}\mathrm{i}^{2}=17 \\
(P=0\end{array}$ & $\begin{array}{l}\text { 20, } d f= \\
\text { 4) }\end{array}$ & $7(P=0$. & $2) ; 1^{2}=5$ & $59 \%$ & 0.05 & $\begin{array}{c}0.2 \\
\text { Favours LVH }\end{array}$ & $\begin{array}{c}5 \\
\text { Favours } \mathrm{HVH}\end{array}$ & 20 \\
\hline
\end{tabular}

Fig. 2 Comparison of surgical site infections (1-year post-operatively) between low-volume and high-volume hospitals 


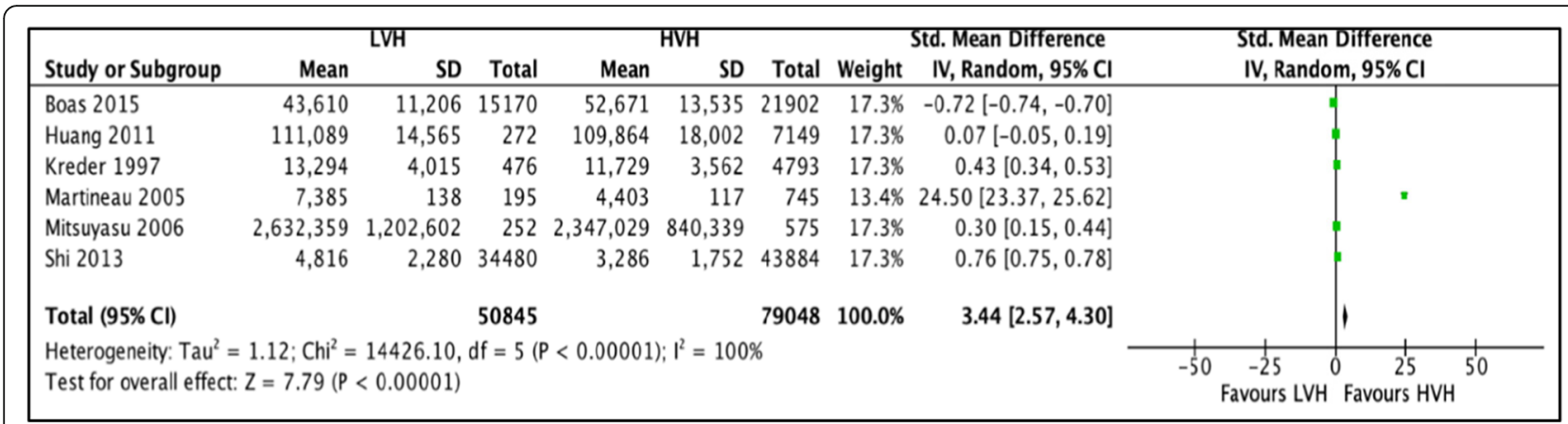

Fig. 3 Comparison of cost of surgery between low-volume and high-volume hospitals

surgical-site infections SSI 1-year postoperatively between $\mathrm{LVH}$ and $\mathrm{HVH}$. We observed that surgical site infections were more frequently observed in $\mathrm{LVH}$ with a risk ratio (RR) of 1.25 (CI $[1.01,1.55] ; I^{2}=59 \%, p$ value $\left.=0.04\right)($ Fig 2 comparison of surgical site infections (1-year postoperatively) between low-volume and high-volume hospitals).

Four studies, which could not be added to the pooledanalysis, also compared postoperative incidence of SSIs. Two of the studies (Kaneko, et al. [41] and Soohoo et al. [42]) reported a significantly higher rate of SSIs following THA at low-volume hospitals while two studies (Huang et al. [43]. and Makela et al. [44]) reported no significant difference between low-volume and highvolume hospitals.

\section{Cost of surgery}

Six studies [34, 36, 43, 45-47] totaling 129,893 hip arthroplasties were pooled to compare the cost of Primary THA in LVH vs. HVH. Based on the results of the random meta-analysis model, we found that the cost of surgery is significantly higher in LVH with SMD of 3.44 (CI $[2.57,4.30] ; I^{2}=100 \%, p$ value < 0.00001) (Fig. 3: comparison of cost of surgery between low-volume and high-volume hospitals).

Three studies reporting differences in the cost of surgery could not be included in the meta-analysis.
Courtney et al. [48] reported that THA procedures performed at $\mathrm{HVH}$ had significantly lower total mean hospital-specific charges. Frisch et al. [49] and Lavernia et al. [50] found no significant difference between mean hospital charges for THA performed at LVH and $\mathrm{HVH}$.

\section{Length of postoperative hospital stay}

A total of 9 studies [36, 37, 41, 43, 45, 46, 51-53] totaling 232,691 hip arthroplasties were pooled to compare the length of postoperative stay in LVH vs. HVH. Based on the results of the random meta-analyses model, we found that postoperative stay was significantly longer in LVH with a SMD of 0.83 (CI $[0.48,1.18] I^{2}=100 \%, p$ value $=0.00001)($ Fig. 4: comparison of length of stay between low-volume and high-volume hospitals.).

Three studies reporting length of stay in low-volume and high-volume hospitals could not be included in the meta-analysis. Doro, et al. [23], Makela et al. [44], and Judge et al. [54] reported increased LOS in LVH as compared to VHVH.

\section{Complications during index hospitalization}

A total of 5 studies [36, 37, 40, 43, 55] totaling 36,159 hip arthroplasties were pooled to compare the complications during index hospitalization between $\mathrm{LVH}$ and $\mathrm{HVH}$. Based on the results of the random meta-analysis

\begin{tabular}{|c|c|c|c|c|c|c|c|c|c|c|c|}
\hline \multirow{3}{*}{$\begin{array}{l}\text { Study or Subgroup } \\
\text { Huang } 2011\end{array}$} & \multicolumn{3}{|c|}{ LVH } & \multicolumn{3}{|c|}{ HVH } & \multicolumn{2}{|r|}{ Std. Mean Difference } & \multirow{2}{*}{\multicolumn{2}{|c|}{$\begin{array}{l}\text { Std. Mean Difference } \\
\text { IV, Random, } 95 \% \mathrm{CI}\end{array}$}} & \\
\hline & \multirow{2}{*}{$\begin{array}{r}\text { Mean } \\
8.74\end{array}$} & \multirow{2}{*}{$\begin{array}{r}\text { SD } \\
3.25\end{array}$} & \multirow{2}{*}{$\begin{array}{r}\text { Total } \\
272\end{array}$} & \multirow{2}{*}{$\begin{array}{r}\text { Mean } \\
7.41\end{array}$} & \multirow{2}{*}{$\begin{array}{r}\text { SD } \\
3.21\end{array}$} & \multirow{2}{*}{$\begin{array}{l}\text { Total } \\
7149\end{array}$} & \multirow{2}{*}{$\begin{array}{r}\text { Weight } \\
11.1 \%\end{array}$} & \multirow{2}{*}{$\begin{array}{r}\text { IV, Random, 95\% CI } \\
0.41[0.29,0.54]\end{array}$} & & & \\
\hline & & & & & & & & & & \multicolumn{2}{|c|}{$=$} \\
\hline Kaneko 2014 & 51.5 & 44 & 2219 & 28.1 & 36.5 & 1894 & $11.2 \%$ & $0.57[0.51,0.64]$ & & $=$ & \\
\hline Kreder 1997 & 6.99 & 4.7126 & 476 & 7.85 & 14.954 & 4793 & $11.1 \%$ & $-0.06[-0.15,0.03]$ & 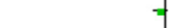 & & \\
\hline Kreder 1998 & 12.8 & 2.566 & 474 & 11.4 & 4.8595 & 1700 & $11.1 \%$ & $0.31[0.21,0.42]$ & & $=$ & \\
\hline Martineau 2005 & 7.4 & 0.4 & 745 & 6.3 & 0.3 & 195 & $10.8 \%$ & $2.88[2.68,3.09]$ & & & - \\
\hline Mitsuyasu 2006 & 58.73 & 32.31 & 252 & 28.76 & 23.47 & 575 & $11.0 \%$ & $1.13[0.97,1.29]$ & & $=$ & \\
\hline Pamilo 2013 & 8.5 & 3.2994 & 12104 & 4.4 & 1.7079 & 11297 & $11.2 \%$ & $1.55[1.52,1.57]$ & & - & \\
\hline Ramkumar 2018 & 3.82 & 5.1241 & 30849 & 3.04 & 7.2466 & 61698 & $11.2 \%$ & $0.12[0.10,0.13]$ & $=$ & - & \\
\hline Styron 2011 & 4.17 & 0.7551 & 50248 & 3.72 & 0.7398 & 45751 & $11.2 \%$ & $0.60[0.59,0.61]$ & & - & \\
\hline Total $(95 \% \mathrm{Cl})$ & & & 97639 & & & 135052 & $100.0 \%$ & $0.83[0.48,1.18]$ & & & \\
\hline \multicolumn{9}{|c|}{$\begin{array}{l}\text { Heterogeneity: } \mathrm{Tau}^{2}=0.29 ; \mathrm{Chi}^{2}=8879.20, \mathrm{df}=8(\mathrm{P}<0.00001) ; \mathrm{I}^{2}=100 \% \\
\text { Test for overall effect: } Z=4.62(\mathrm{P}<0.00001)\end{array}$} & \multicolumn{2}{|c|}{ Favours LVH Favours HVH } & \\
\hline
\end{tabular}

Fig. 4 Comparison of length of stay between low-volume and high-volume hospitals 


\begin{tabular}{|c|c|c|c|c|c|c|c|c|c|c|}
\hline Study or Subgroup & \multicolumn{2}{|l|}{ LVH } & \multicolumn{2}{|c|}{$\mathrm{HVH}$} & Weight & \multicolumn{2}{|l|}{ Risk Ratio } & \multicolumn{2}{|c|}{$\begin{array}{c}\text { Risk Ratio } \\
\text { M-H, Random, } 95 \% \mathrm{Cl}\end{array}$} & \\
\hline Huang 2011 & 6 & 272 & 98 & 7149 & $16.1 \%$ & $1.61[0.71,3.64]$ & & & & \\
\hline Kreder 1997 & 35 & 476 & 436 & 4793 & $21.3 \%$ & $0.81[0.58,1.13]$ & & & & \\
\hline Kreder 1998 & 32 & 474 & 151 & 1700 & $21.0 \%$ & $0.76[0.53,1.10]$ & & & & \\
\hline Laura 2011 & 60 & 2398 & 115 & 8813 & $21.5 \%$ & $1.92[1.41,2.61]$ & & & $\rightarrow-$ & \\
\hline Paterson 2010 & 25 & 5303 & 67 & 4781 & $20.1 \%$ & $0.34[0.21,0.53]$ & & $\rightarrow$ & & \\
\hline Total $(95 \% \mathrm{Cl})$ & & 8923 & & 27236 & $100.0 \%$ & $0.90[0.49,1.64]$ & & & & \\
\hline Total events & 158 & & 867 & & & & & & & \\
\hline $\begin{array}{l}\text { Heterogeneity: } \text { Tau }^{2} \\
\text { Test for overall effect }\end{array}$ & $\begin{array}{l}0.42 ; C r \\
Z=0.34\end{array}$ & $\begin{array}{l}i^{2}=4 \\
(P=C\end{array}$ & $\begin{array}{l}4.03, \mathrm{df}= \\
.73)\end{array}$ & $=4(P<$ & $.00001)$ & $; I^{2}=91 \%$ & 0.01 & $\begin{array}{ll}0.1 & 1 \\
\text { Favours LVH } & \end{array}$ & $\begin{array}{r}10 \\
\text { Favours HVH }\end{array}$ & 100 \\
\hline
\end{tabular}

Fig. 5 Comparison of complications during index hospitalization between low-volume and high-volume hospitals

model, we found that there is no significant difference in rates of index hospitalization complications between $\mathrm{LVH}$ and $\mathrm{HVH}$, with RR $=0.90$ (CI $[0.49,1.64] I^{2}=91 \%$, $p$ value $=0.73$ ) (Fig. 5: comparison of complications during index hospitalization between low-volume and highvolume hospitals.).

\section{Complications within 90 days postoperatively}

A total of 3 studies $[42,55,56]$ totaling 74,409 hip arthroplasties were pooled to compare the rates of complications 90 days postoperatively in $\mathrm{LVH}$ with $\mathrm{HVH}$. Based on the results of the random meta-analyses model, we found that there is a significantly higher chance of 90-day complications in $\mathrm{LVH}$ as compared to $\mathrm{HVH}(\mathrm{RR}=1.80$ (CI [1.50, 2.17] $I^{2}=52 \%, p$ value $<0.00001$ ) (Fig. 6: comparison of complications 90 days postoperatively between lowvolume and high-volume hospitals).

Although not included in the meta-analysis, Solomon et al. and Katz (2001) et al. also report a higher incidence of postoperative complications in LVH compared to $\mathrm{HVH}$.

\section{Revision hip arthroplasty at 1-year postoperative}

A total of 5 studies [36, 37, 40, 42, 57] totaling 361,440 hip arthroplasties were pooled to compare the rates of revision THA between LVH and HVH. Based on the pooled analysis, no significant difference was observed between rate of revisions for surgeries performed in $\mathrm{LVH}$ and
HVH 1 year postoperatively; $\mathrm{RR}=1.27\left(\mathrm{CI}[0.98,1.65] I^{2}\right.$ $=73 \%, p$ value $=0.07$ ) (Fig. 7: comparison of revision hip arthroplasty 1 year postoperatively between low-volume and high-volume hospitals).

\section{Revision hip arthroplasty at 3 years postoperative}

Five studies [22, 57-60] totaling 509,155 hip arthroplasties were pooled. No significant difference was observed between rate of revisions for surgeries performed in $\mathrm{LVH}$ and $\mathrm{HVH}$; RR $=1.18\left(\mathrm{CI}[0.86,1.62] I^{2}=97 \%, p\right.$ value $=0.31$ ) (Fig. 8: comparison of revision hip arthroplasty 3 years postoperative between low-volume and high-volume hospitals).In addition to this, Pamilo et al. [51], Makela et al. [44], and Manley et al. [61] also reported that there was no significant association between revision rates and hospital volume. In contrast, Judge et al. [54] reported a higher hazard ratio of revision arthroplasty 5 years postoperatively for HVH vs. LVH.

\section{0-day mortality}

Three studies [21, 33, 62] totaling 140,656 hip arthroplasties were pooled to compare the mortality rates within 30 days postoperatively between $\mathrm{LVH}$ and $\mathrm{HVH}$. Based on the results of the random meta-analysis model, we found a significantly higher mortality rate in $\mathrm{LVH}$, $\mathrm{RR}=2.33\left(\mathrm{CI}[1.27,4.28] I^{2}=93 \%, p\right.$ value $\left.=0.006\right)$ (Fig. 9: comparison of 30-day mortality between low-

\begin{tabular}{|c|c|c|c|c|c|c|c|c|c|c|}
\hline Study or Subgroup & \multicolumn{2}{|c|}{ LVH } & \multicolumn{2}{|c|}{ HVH } & Weight & Risk Ratio & \multicolumn{4}{|c|}{$\begin{array}{c}\text { Risk Ratio } \\
\text { M-H, Random, } 95 \% \mathrm{Cl}\end{array}$} \\
\hline Camberlain 2011 & 54 & 1327 & 208 & 7281 & $24.1 \%$ & $1.42[1.06,1.91]$ & & & - & \\
\hline Laura 2011 & 205 & 18594 & 51 & 8813 & $23.0 \%$ & $1.91[1.40,2.59]$ & & & $\rightarrow$ & \\
\hline Soohoo 2010 & 2036 & 54488 & 523 & 27480 & $52.9 \%$ & $1.96[1.79,2.16]$ & & & [ & \\
\hline Total $(95 \% \mathrm{Cl})$ & & 74409 & & 43574 & $100.0 \%$ & $1.80[1.50,2.17]$ & & & $\bullet$ & \\
\hline Total events & 2295 & & 782 & & & & & & & \\
\hline $\begin{array}{l}\text { Heterogeneity: } \mathrm{Tau}^{2}= \\
\text { Test for overall effect }\end{array}$ & $\begin{array}{l}0.01 ; C h \\
Z=6.25\end{array}$ & $\begin{array}{l}\mathrm{i}^{2}=4.1 \\
(\mathrm{P}<0 . \mathrm{C}\end{array}$ & $\begin{array}{l}7, d f=2 \\
00001)\end{array}$ & $(P=0$. & $12) ; I^{2}=$ & $52 \%$ & 0.01 & $\begin{array}{l}0.1 \\
\text { Favours LVH }\end{array}$ & $\begin{array}{r}10 \\
10 \\
\text { Favours HVH }\end{array}$ & 100 \\
\hline
\end{tabular}

Fig. 6 Comparison of complications 90 days postoperatively between low-volume and high-volume hospitals 


\begin{tabular}{|c|c|c|c|c|c|c|c|c|c|c|}
\hline \multirow[b]{2}{*}{ Study or Subgroup } & \multicolumn{2}{|c|}{ LVH } & \multicolumn{2}{|c|}{ HVH } & \multirow[b]{2}{*}{ Weight } & \multirow{2}{*}{$\begin{array}{c}\text { Risk Ratio } \\
\text { M-H, Random, } 95 \% \mathrm{CI}\end{array}$} & \multirow{2}{*}{\multicolumn{3}{|c|}{$\begin{array}{c}\text { Risk Ratio } \\
\text { M-H, Random, } 95 \% \mathrm{Cl}\end{array}$}} & \\
\hline & Events & Total & Events & Total & & & & & & \\
\hline Glassou 2016 & 864 & 139778 & 630 & 122156 & $32.6 \%$ & $1.20[1.08,1.33]$ & & & $=$ & \\
\hline Kreder 1997 & 12 & 476 & 81 & 4793 & $12.1 \%$ & $1.49[0.82,2.72]$ & & & & \\
\hline Kreder 1998 & 3 & 474 & 24 & 1700 & $4.1 \%$ & $0.45[0.14,1.48]$ & & & & \\
\hline Paterson 2010 & 95 & 5303 & 83 & 4781 & $23.9 \%$ & $1.03[0.77,1.38]$ & & - & & \\
\hline Soohoo 2010 & 346 & 54488 & 98 & 27480 & $27.3 \%$ & $1.78[1.42,2.23]$ & & & $\rightarrow-$ & \\
\hline Total $(95 \% \mathrm{Cl})$ & & 200519 & & 160910 & $100.0 \%$ & $1.27[0.98,1.65]$ & & & & \\
\hline \multirow{2}{*}{\multicolumn{7}{|c|}{$\begin{array}{l}\text { Teterogeneity: } \text { Tau }^{2}=0.05 ; \text { Chi }^{2}=15.07, d f=4(P=0.005) ; I^{2}=73 \% \\
\text { Test for overall effect: } Z=1.81(P=0.07)\end{array}$}} & & & & \\
\hline & & & & & & & 0.2 & $\begin{array}{c}0.51 \\
\text { Favours LVH }\end{array}$ & \begin{tabular}{c|}
2 \\
Favours HVH
\end{tabular} & 5 \\
\hline
\end{tabular}

Fig. 7 Comparison of revision hip arthroplasty 1 year postoperatively between low-volume and high-volume hospitals

volume and high-volume hospitals (study by Taylor et al. reported findings from 1994 and 1995 separately).

\section{0-day mortality}

A total of 4 studies [35-37, 40] totaling 58,688 hip arthroplasties were pooled to compare mortality rates within 90 days postoperatively between $\mathrm{LVH}$ and $\mathrm{HVH}$. Based on the results of the random meta-analysis model, we found a significantly higher mortality rate in $\mathrm{LVH}, \mathrm{RR}=1.26\left(\mathrm{CI}[1.05,1.51] I^{2}=0 \%, p\right.$ value $\left.=0.01\right)$ (Fig. 10: comparison of 90-day mortality between lowvolume and high-volume hospitals.).

\section{1-year mortality}

Four studies, [36, 37, 62, 63] totaling 13,203 hip arthroplasties were pooled to compare mortality rates within 1 year postoperatively between LVH and HVH. Based on the results of the random meta-analysis model, we see that there is a significantly higher mortality rate in $\mathrm{LVH}, \mathrm{RR}=$ 2.26 (CI [1.32, 3.88] $I^{2}=72 \%, p$ value $=0.003$ ) (Fig. 11: comparison of 1-year mortality between low-volume and high-volume hospitals.).

A few studies reporting postoperative mortality as an outcome could not be included in the meta-analysis. Two studies (Lavernia et al. [50] and Laura et al. [55]) stated no statistically significant difference in mortality rates between $\mathrm{LVH}$ and $\mathrm{HVH}$. However 7 studies (Hughes et al. [64], Solomon et al. [65], Sharkey et al.
[66], Riley et al. [67], Judge et al. [54], Chien et al. [68], and Doro et al. [23]) reported a significant inverse relation between hospital volume and mortality rate.

\section{Postoperative thromboembolic events}

Five studies, [35-37, 42] totaling 130,572 hip arthroplasties were pooled to compare the rates post-operative deep venous thrombosis between LVH and $\mathrm{HVH}$. Based on the results of the random meta-analysis model, we found that there was no significant difference in the risk of thromboembolic events 90 days postop; $(\mathrm{RR}=1.16$, $\left(\mathrm{CI}[0.78,1.72] I^{2}=78 \%, p\right.$ value $\left.=0.46\right)$ (Fig. $12:$ comparison of postoperative deep venous thrombosis between low-volume and high-volume hospitals.).

\section{Quality appraisal}

All the studies included in this review are observational studies, with 42 retrospective and 2 prospective, which are considered low-grade studies as per the GRADE system guidelines.

\section{Discussion}

Few systematic reviews have been conducted in the realm of orthopedic surgery to study the volumeoutcome relationship. While knee arthroplasty [69], shoulder arthroplasty [70], spine surgery [71], and hip fractures [72] have been extensively studied, evidence of

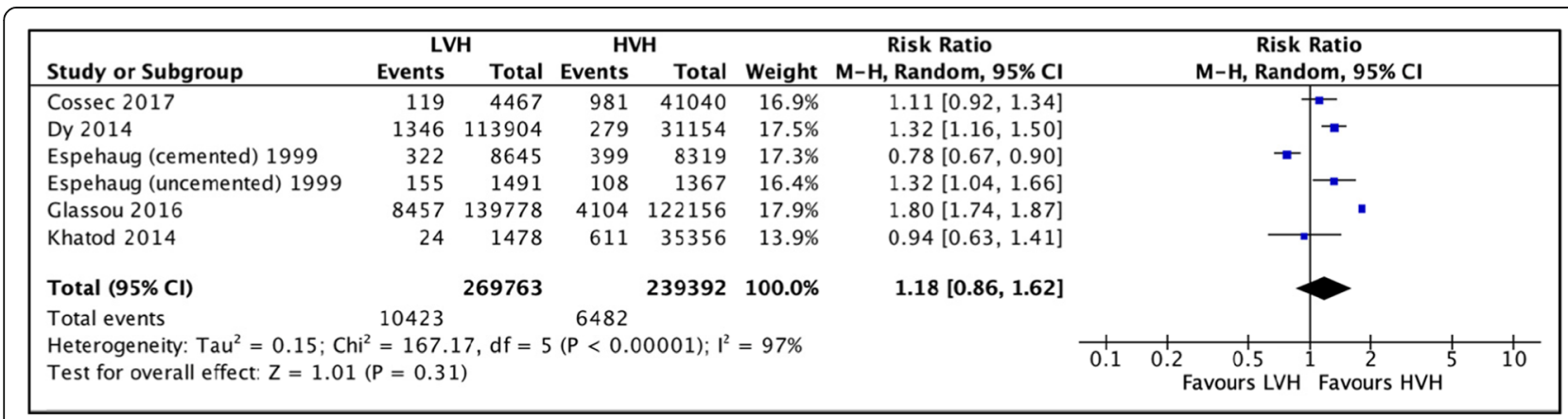

Fig. 8 Comparison of revision hip arthroplasty 3-year postoperative between low-volume and high-volume hospitals 


\begin{tabular}{|c|c|c|c|c|c|c|c|c|c|c|}
\hline Study or Subgroup & \multicolumn{2}{|l|}{ LVH } & \multicolumn{2}{|c|}{ HVH } & \multicolumn{2}{|r|}{ Risk Ratio } & \multicolumn{4}{|c|}{$\begin{array}{c}\text { Risk Ratio } \\
\text { M-H, Random, } 95 \% \mathrm{Cl}\end{array}$} \\
\hline Crouse 2017 & 35 & 1490 & 140 & 5605 & $26.8 \%$ & $0.94[0.65,1.36]$ & & & & \\
\hline Singh 2011 & 6 & 814 & 9 & 2964 & $16.0 \%$ & $2.43[0.87,6.80]$ & & & & \\
\hline Taylor 1994 & 166 & 4723 & 679 & 64664 & $29.0 \%$ & $3.35[2.83,3.96]$ & & & $=$ & \\
\hline Taylor 1995 & 76 & 2266 & 320 & 35541 & $28.3 \%$ & $3.73[2.91,4.77]$ & & & $\rightarrow$ & \\
\hline Total $(95 \% \mathrm{Cl})$ & & 9293 & & 108774 & $100.0 \%$ & $2.33[1.27,4.28]$ & & & & \\
\hline Total events & 283 & & 1148 & & & & & & & \\
\hline $\begin{array}{l}\text { Heterogeneity: } \mathrm{Tau}^{2}= \\
\text { Test for overall effect }\end{array}$ & $\begin{array}{l}0.32 ; C h \\
Z=2.74\end{array}$ & $\begin{array}{l}\mathrm{i}^{2}=45 \\
(\mathrm{P}=0\end{array}$ & $\begin{array}{l}.27, \mathrm{df}= \\
.006)\end{array}$ & $3(P<0$ & $.00001)$; & $I^{2}=93 \%$ & 0.01 & $\begin{array}{l}0.1 \\
\text { Favours LVH }\end{array}$ & $\begin{array}{r}10 \\
\text { Favours HVH }\end{array}$ & 100 \\
\hline
\end{tabular}

Fig. 9 Comparison of 30-day mortality between low-volume and high-volume hospitals (study by Taylor et al. reported findings from 1994 to 1995 separately)

the effect of hospital volume on total hip arthroplasty has not been reviewed systematically to our knowledge.

Our review was based on observational studies from several countries around the world with a predominant contribution from the USA. In our review, we found that THAs performed at LVH have a significantly higher risk of surgical site infections, cost of surgery, length of stay, 90-day complications, and mortality (30-days, 90 days, and 1 year) (Table 2).

We found a significantly higher risk of postoperative surgical site infections (SSIs) in LVH compared with $\mathrm{HVH}$. The finding of SSI risk being higher in LVH as compared to HVH may be linked to other factors. Previous literature has reported the association of SSIs with a longer length of hospital stay and has linked a longer length of stay to low-volume hospitals [73, 74]. Another risk factor associated with SSIs is longer operative duration which has also been observed in low-volume hospitals in previous literature [31, 75, 76]. In addition, previous literature suggests that high-volume hospitals may enjoy superior infection prevention measures [77]. Our results, though specific to THA, are in agreement with findings of prior research showing higher risks of SSI in LVH $[78,79]$.

Our findings also show an inverse relationship between hospital volume and cost of surgery. This may be attributed to greater negotiating power of high-volume hospitals because of higher numbers, greater efficiency, and accelerated care pathways allowing expedited discharge processes and more prudent use of ancillary services at $\mathrm{HVH}$ resulting in significant cost savings for the healthcare system and the patient [80].

Length of stay may be a complex variable to dissect as it is a combined reflection of pre-operative, intraoperative, and postoperative care. Previous literature has reported associations among operative time, postoperative complications, and length of stay [81-83]. Though we did not find a significant difference between the postoperative complications in $\mathrm{HVH}$ and $\mathrm{LVH}$ during their hospital stay in our study, the key factors underlying this complex relationship are potentially related to the superior healthcare provision capacity of $\mathrm{HVH}$ including availability of special care facility, infrastructure, specialist medicine care, physiotherapy, pain control anesthesia teams, and other resources during all stages of care and health economy of the country the study was conducted in $[35,84]$. This enables the hospitals to be better equipped to deal with problems before they escalate to serious complications $[85,86]$. Although several intraoperative factors may also play a role in determining the length of stay between $\mathrm{HVH}$ and $\mathrm{LVH}$, this has not been studied in detail.

Although our findings show no significant difference between complications during the hospital stay, complications

\begin{tabular}{|c|c|c|c|c|c|c|c|c|c|c|}
\hline Study or Subgroup & \multicolumn{2}{|c|}{ LVH } & \multicolumn{2}{|c|}{ HVH } & Weight & \multicolumn{2}{|l|}{ Risk Ratio } & \multicolumn{2}{|c|}{$\begin{array}{c}\text { Risk Ratio } \\
\text { M-H, Random, 95\% Cl }\end{array}$} & \\
\hline Katz 2001 & 226 & 20638 & 173 & 20523 & $83.3 \%$ & $1.30[1.07,1.58]$ & & & & \\
\hline Kreder 1997 & 3 & 476 & 29 & 4793 & $2.3 \%$ & $1.04[0.32,3.41]$ & & & & \\
\hline Kreder 1998 & 3 & 474 & 14 & 1700 & $2.1 \%$ & $0.77[0.22,2.66]$ & & & & \\
\hline Paterson 2010 & 33 & 5303 & 26 & 4781 & $12.3 \%$ & $1.14[0.69,1.91]$ & & 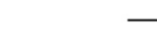 & - & \\
\hline Total $(95 \% \mathrm{Cl})$ & & 26891 & & 31797 & $100.0 \%$ & $1.26[1.05,1.51]$ & & & 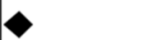 & \\
\hline Total events & 265 & & 242 & & & & & & & \\
\hline $\begin{array}{l}\text { Heterogeneity: } \text { Tau }^{2}= \\
\text { Test for overall effect }\end{array}$ & $\begin{array}{l}0.00 ; C h \\
z=2.51\end{array}$ & $\begin{array}{l}\mathrm{il}^{2}=0.93 \\
(\mathrm{P}=0.0\end{array}$ & 3, $d f=3$ & $(P=0.8$ & $32) ; 1^{2}=($ & & 0.05 & $\begin{array}{l}1 \\
0.2 \\
\text { Favours LVH }\end{array}$ & \begin{tabular}{|c|c|} 
& 1 \\
& 5 \\
Favours HVH
\end{tabular} & $\frac{1}{20}$ \\
\hline
\end{tabular}

Fig. 10 Comparison of 90-day mortality between low-volume and high-volume hospitals. 


\begin{tabular}{|c|c|c|c|c|c|c|c|c|c|}
\hline Study or Subgroup & $\begin{array}{l}\text { LVH } \\
\text { Events }\end{array}$ & Total & $\begin{array}{c}\text { HVH } \\
\text { Events }\end{array}$ & Total & Weight & $\begin{array}{c}\text { Risk Ratio } \\
\text { M-H, Random, } 95 \% \mathrm{CI}\end{array}$ & $\begin{array}{r}\text { Risk R } \\
\text { M-H, Rando }\end{array}$ & $\begin{array}{l}\text { Ratio } \\
\text { om, } 95 \% \mathrm{Cl}\end{array}$ & \\
\hline Kreder 1997 & 8 & 476 & 62 & 4793 & $21.6 \%$ & $1.30[0.63,2.70]$ & 7 & $\because$ & \\
\hline Kreder 1998 & 10 & 474 & 24 & 1700 & $21.6 \%$ & $1.49[0.72,3.10]$ & & $=$ & \\
\hline Maceroli 2015 & 302 & 1667 & 24 & 315 & $29.9 \%$ & $2.38[1.60,3.54]$ & & $\rightarrow-$ & \\
\hline Singh 2011 & 32 & 814 & 25 & 2964 & $26.9 \%$ & $4.66[2.78,7.82]$ & & $\longrightarrow$ & \\
\hline Total $(95 \% \mathrm{Cl})$ & & 3431 & & 9772 & $100.0 \%$ & $2.26[1.32,3.88]$ & & 6 & \\
\hline Total events & 352 & & 135 & & & & & & \\
\hline \multicolumn{7}{|c|}{$\begin{array}{l}\text { Heterogeneity: } \mathrm{Tau}^{2}=0.21 ; \mathrm{Chi}^{2}=10.63, \mathrm{df}=3(\mathrm{P}=0.01) ; \mathrm{I}^{2}=72 \% \\
\text { Test for overall effect: } \mathrm{Z}=2.97(\mathrm{P}=0.003)\end{array}$} & $\begin{array}{lll}0.01 & 0.1 & 1 \\
\text { Favours [experimental] }\end{array}$ & $\begin{array}{c}10 \\
\text { Favours [control] }\end{array}$ & 100 \\
\hline
\end{tabular}

Fig. 11 Comparison of 1-year mortality between low-volume and high-volume hospitals

at 90 days were reported to be significantly higher in $\mathrm{LVH}$ when compared to HVH. Soohoo [42] studied this extensively and concluded that patient and surgeon factors heavily influenced the risk of developing complications. Patient factors associated with higher 90-day complications included male gender, higher Charlson comorbidity score, comorbid conditions such as diabetes and rheumatoid arthritis [42]. While these may not be under the control of the hospital, a shorter learning curve [87] in the presence of better resources $[85,86,88]$ may allow an increase in the capacity of $\mathrm{HVH}$ to be proactive in identifying and resolving issues before they can adversely influence outcomes. Although our results show a higher 90-day complication rate with low-volume hospitals, there is no significant difference in 1-year and 3-year revision rates between $\mathrm{LVH}$ and $\mathrm{HVH}$. This may be due to possible loss to follow-up, visit to high-volume hospitals for revisions or mortality (as seen in our findings).

From a monetary perspective, not only are hip replacement surgeries at $\mathrm{HVH}$ cost-effective, they also have a greater value per dollar spent in the long run as they are associated with lower rates of complications, especially surgical site infections. SSIs result in significant losses with up to three-fold cost increase after orthopedic surgeries [89]. This is particularly alarming as the rates of surgical site infections in the USA are on the rise $[5,90-$ 92] and reimbursements are being reduced or denied [93]. Lower rates of 90-day complications are not only better outcomes, but also saves the costs of readmission. Additionally, $\mathrm{HVH}$ may have room to negotiate costs with suppliers due to their large volumes. This translates into decreased costs which benefit the patients and the healthcare system.

In contrast, longer length of stay associated with LVH following THA procedures leads to a significant overall increase in expenditure. In total, around 300,000 THA procedures are carried out annually in the USA [94]. Up to $35 \%(105,000)$ of these are carried out in LVH [35, 95]. Given that the cost of 1 day of in-patient stay at a hospital in the USA is approximately $\$ 2500$ [96], each additional day of stay is an additional annual expenditure of $\$ 262,500,000$. This is excluding additional costs incurred due to the higher rates of SSI and other shortterm (90-day post-THA) complications associated with having THA at $\mathrm{LVH}$.

Although there is much debate on the influence of experience of the surgeon and outcomes [97, 98], lower mortality rate at 30 days, 90 days, and 1-year postoperatively in HVHs following hip arthroplasty may be because health care professionals including doctors and staff may have more experience and skill at $\mathrm{HVH}$, with highly evolved and efficient processes of patient care (such as tailored diagnostic and treatment algorithms or guidelines), leading to better patient outcomes [99, 100]. In addition to this, the larger workforce and more system-level resources to use in patient care allow HVHs to tackle unanticipated complications at all stages of care [99].

The better outcomes observed in HVH may best be explained by two popular hypotheses which contribute to positive feedback. First, "practice makes perfect"

\begin{tabular}{|c|c|c|c|c|c|c|c|c|}
\hline Study or Subgroup & \multicolumn{2}{|c|}{ LVH } & $\begin{array}{c}\text { HVH } \\
\text { Events }\end{array}$ & Total & Weight & $\begin{array}{c}\text { Risk Ratio } \\
\text { M-H, Random, } 95 \% \mathrm{Cl}\end{array}$ & \multicolumn{2}{|c|}{$\begin{array}{ll} & \text { Risk Ratio } \\
\mathrm{M}-\mathrm{H}, \text { Random, } 95 \% \mathrm{Cl}\end{array}$} \\
\hline Katz 2001 & 213 & 20638 & 164 & 20523 & $35.1 \%$ & $1.29[1.05,1.58]$ & & - \\
\hline Kreder 1997 & 4 & 476 & 58 & 4793 & $11.0 \%$ & $0.69[0.25,1.90]$ & & \\
\hline Kreder 1998 & 11 & 474 & 66 & 1700 & $19.5 \%$ & $0.60[0.32,1.12]$ & & \\
\hline Soohoo 2010 & 346 & 54488 & 98 & 27480 & $34.4 \%$ & $1.78[1.42,2.23]$ & & - \\
\hline Total $(95 \% \mathrm{Cl})$ & & 76076 & & 54496 & $100.0 \%$ & $1.16[0.78,1.72]$ & & \\
\hline Total events & 574 & & 386 & & & & & \\
\hline \multicolumn{7}{|c|}{$\begin{array}{l}\text { Heterogeneity: } \mathrm{Tau}^{2}=0.11 ; \mathrm{Chi}^{2}=13.91, \mathrm{df}=3(\mathrm{P}=0.003) ; \mathrm{I}^{2}=78 \% \\
\text { Test for overall effect: } \mathrm{Z}=0.73(\mathrm{P}=0.46)\end{array}$} & 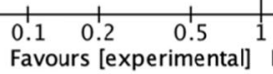 & $\begin{array}{ccc} & 1 & 1 \\
\text { Favours [control] } & 10\end{array}$ \\
\hline
\end{tabular}

Fig. 12 Comparison of postoperative deep venous thrombosis between low-volume and high-volume hospitals 
Table 2 Summary of findings

\begin{tabular}{|c|c|c|c|c|}
\hline Outcome & Studies & Hips & Risk ratio & Significance \\
\hline Postoperative surgical site infection & 8 & 200,950 & $\begin{array}{l}1.25 \\
\mathrm{Cl}[1.01,1.55]\end{array}$ & 0.04 \\
\hline Cost of surgery & 6 & 129,893 & $\begin{array}{l}3.44 \\
\mathrm{Cl}[2.57,4.30]\end{array}$ & $<0.00001$ \\
\hline Postoperative length of hospital Stay & 9 & 232,691 & $\begin{array}{l}0.83 \\
\mathrm{Cl}[0.48,1.18]\end{array}$ & $<0.00001$ \\
\hline Complications during index hospitalization & 5 & 36,159 & $\begin{array}{l}0.90 \\
\mathrm{Cl}[0.49,1.64]\end{array}$ & 0.73 \\
\hline Complication within 90 days post-op & 3 & 74,409 & $\begin{array}{l}1.80 \\
\text { Cl }[1.50,2.17]\end{array}$ & $<0.00001$ \\
\hline Revision arthroplasty within 1 year post-op & 5 & 361,440 & $\begin{array}{l}1.27 \\
\text { Cl }[0.98,1.65]\end{array}$ & 0.07 \\
\hline Long-term revision arthroplasty & 5 & 509,155 & $\begin{array}{l}1.18 \\
\mathrm{Cl}[0.86,1.62]\end{array}$ & 0.31 \\
\hline 30-day mortality & 3 & 140,656 & $\begin{array}{l}2.33 \\
\text { Cl }[1.27,4.28]\end{array}$ & 0.006 \\
\hline 90-day mortality & 4 & 58,688 & $\begin{array}{l}1.26 \\
\mathrm{Cl}[1.05,1.51]\end{array}$ & 0.01 \\
\hline 1-year mortality & 4 & 13,203 & $\begin{array}{l}2.26 \\
\mathrm{Cl}[1.32,3.88]\end{array}$ & 0.003 \\
\hline Postoperative thromboembolic events & 5 & 147,015 & $\begin{array}{l}1.28 \\
\text { Cl }[0.92,1.77]\end{array}$ & 0.15 \\
\hline
\end{tabular}

Cl confidence interval

*Risk ratio for low-volume hospitals in comparison to high-volume hospitals

which means hospitals develop more effective skills as they treat more patients [100] and second "selective referral" where physicians and hospitals with better outcomes receive more referrals subsequently acquiring larger volumes [101].

\section{Limitations}

There are several caveats in our study. We were not able to review the intra-operative factors and the functional rehabilitation of patients for comparison between $\mathrm{LVH}$ and HVHs. This was because no studies have compared these variables among LVH and HVHs. Additionally, the hospital volume cutoff is not uniform across studies. Katz [35] used $<10$ procedures per year as the cut-off, while Laucis [102] set $<100$ cases per year as LVH. This could be due to the rising popularity of arthroplasty to treat end-stage osteoarthritis where the number of THA and TKA increased from 343,000 in 2000 to 851,000 in 2012 and is further on the rise. Hospitals now perform this procedure more frequently, and understandably, the cut-offs have been raised over time as observed in more recent studies. Studies have been conducted in 12 unique countries and variatons in volume thresholds may have been contributed by economical, logistic, and disease burden differences. Lastly, our review is based on observational studies. Conducting a randomized control trial (RCT) may have ethical and logistical barriers. Even after 30 years of the first study comparing the outcomes of THA in LVH and HVH, no RCT has been reported. There is a need for stronger evidence, including prospective cohorts, to re-visit this important topic using larger datasets to define objective volume-thresholds/ benchmarks.

\section{Conclusion}

Our analysis shows that total hip arthroplasties performed at low-volume hospitals have significantly higher surgical site infection rates, length of stay, cost of surgery, 90-day complications, and mortality rates (30 days, 90 days, and 1 year) compared with high-volume hospitals. Randomized controlled trials and prospective studies should be conducted to assess differences in functional outcomes and intra-operative factors between low-volume and high-volume hospitals using standardized cut-offs for low- and high-volume hospitals.

\section{Supplementary information}

Supplementary information accompanies this paper at https://doi.org/10. 1186/s13018-019-1531-0.

Additional file 1. Study characteristics.

Additional file 2. Covariate adjustment.

Additional file 3. Findings from each study (extracted data).

Additional file 4: Table S4. Hospital Volume Thresholds and Outcomes in Studies of Primary Total Hip Arthroplasty (pTHA).

Additional file 5. Comorbids reported across studies. 


\section{Abbreviations}

ASA: American Society of Anesthesiologists; HVH: High-volume hospital; LOS: Length of stay; LVH: Low-volume hospital; RR: Risk ratio; SMD: Standard mean difference; SSI: Surgical site infection; THA: Total hip arthroplasty

\section{Acknowledgements}

None

\section{Authors' contributions}

SHM contributed to the conceptualization, formal analysis, methodology, project administration, visualization, and writing —original draft. MAOG contributed to the data curation, methodology, and validation. RSM contributed to the data curation, visualization, and writing-original draft. NQQ contributed to the data curation, visualization, writing-review and editing. SAM contributed to the conceptualization and data curation. ATM contributed to the validation, writing-review and editing. SN contributed to the conceptualization, supervision, and writing - review and editing. All authors read and approved the final manuscript.

\section{Funding}

No funding received

\section{Availability of data and materials}

The datasets used and/or analysed during the current study are available from the corresponding author on reasonable request.

\section{Ethics approval and consent to participate}

This study is a systematic review hence ethics approval was waived. The study is registered with Research Registry: reviewregistry730.

\section{Consent for publication}

Not applicable

\section{Competing interests}

The authors declare that they have no competing interests.

\section{Author details}

'Department of Biological and Biomedical Sciences, Aga Khan University, Karachi, Pakistan. ${ }^{2}$ Department of Pediatric Surgery, Vanderbilt University Medical Center, Nashville, Tennessee, USA. ${ }^{3}$ Medical College, Aga Khan University, Karachi, Pakistan. ${ }^{4}$ Department of Medicine, Aga Khan University, Karachi, Pakistan. ${ }^{5}$ Medical College, Khyber Girls Medical College, Peshawar, Pakistan. ${ }^{6}$ Department of Orthopedics, Ohio State University, Columbus, Ohio, USA. ${ }^{7}$ Department of Orthopedic Surgery, Aga Khan University, Karachi, Pakistan.

Received: 29 August 2019 Accepted: 19 December 2019

Published online: 27 December 2019

\section{References}

1. Beswick AD, Wylde V, Gooberman-Hill R, Blom A, Dieppe P. What proportion of patients report long-term pain after total hip or knee replacement for osteoarthritis? A systematic review of prospective studies in unselected patients. BMJ open. 2012;2(1):e000435.

2. Vissers MM, Bussmann JB, Verhaar JA, Arends LR, Furlan AD, Reijman M. Recovery of physical functioning after total hip arthroplasty: systematic review and meta-analysis of the literature. Physical Therapy. 2011;91(5): $615-29$.

3. Harris $W H$, Sledge CB. Total hip and total knee replacement. N E J Med. 1990;323(11):725-31.

4. Daigle ME, Weinstein AM, Katz JN, Losina E. The cost-effectiveness of total joint arthroplasty: a systematic review of published literature. Best Pract Res Clin Rheumatol. 2012;26(5):649-58.

5. Kurtz S, Ong K, Lau E, Mowat F, Halpern M. Projections of primary and revision hip and knee arthroplasty in the United States from 2005 to 2030 JBJS. 2007:89(4):780-5.

6. Learmonth ID, Young $C$, Rorabeck $C$. The operation of the century: total hip replacement. Lancet. 2007;370(9597):1508-19.

7. Berry DJ, Harmsen WS, Cabanela ME, Morrey BF. Twenty-five-year survivorship of two thousand consecutive primary Charnley total hip replacements: factors affecting survivorship of acetabular and femoral components. JBJS. 2002:84(2):171-7.

8. Huddleston Jl, Wang Y, Uquillas C, Herndon JH, Maloney WJ. Age and obesity are risk factors for adverse events after total hip arthroplasty. Clin Orthop Relat Res. 2012;470(2):490-6.

9. Whittle J, Steinberg EP, Anderson GF, Herbert R, Hochberg MC. Mortality after elective total hip arthroplasty in elderly Americans. Age, gender, and indication for surgery predict survival. Clin Orthop Relat Res. 1993;295:119-26.

10. Lavernia CJ, Alcerro JC, Contreras JS, Rossi MD. Patient perceived outcomes after primary hip arthroplasty: does gender matter? Clin Orthop Relat Res. 2011:469(2):348-54.

11. Alvi HM, Mednick RE, Krishnan V, Kwasny MJ, Beal MD, Manning DW. The effect of BMI on 30 day outcomes following total joint arthroplasty. J Arthroplasty. 2015;30(7):1113-7.

12. Loth FL, Giesinger JM, Giesinger K, MacDonald DJ, Simpson AHR, Howie CR, et al. Impact of comorbidities on outcome after total hip arthroplasty. J Arthroplasty. 2017:32(9):2755-61.

13. Bozic KJ, Lau E, Kurtz S, Ong K, Rubash H, Vail TP, et al. Patient-related risk factors for periprosthetic joint infection and postoperative mortality following total hip arthroplasty in Medicare patients. JBJS. 2012;94(9):794-800.

14. Pugely AJ, Callaghan JJ, Martin CT, Cram P, Gao Y. Incidence of and risk factors for 30-day readmission following elective primary total joint arthroplasty: analysis from the ACS-NSQIP. J Arthroplasty. 2013;28(9): 1499-504.

15. Kheir MM, Kheir YNP, Tan TL, Ackerman CT, Rondon AJ, Chen AF. Increased Complications for Schizophrenia and Bipolar Disorder Patients Undergoing Total Joint Arthroplasty. J Arthroplasty. 2018:33(5):1462-6.

16. Edusei E, Kim KY, Anoushiravani AA, Yu S, Steiger D, Slover JD. Prevalence of neurocognitive dysfunction and its effects on postoperative outcomes in total joint arthroplasty. J Arthroplasty. 2018:33(2):350-4.

17. Varnum C. Outcomes of Different Bearing in Total Hip Arthroplasty: Implant Survival, Revision Causes, and Patient-reported Outcome: Syddansk Universitet; 2016.

18. Singh SP, Bhalodiya HP. Head size and dislocation rate in primary total hip arthroplasty. Indian J Orthop. 2013;47(5):443.

19. Kim M-W, Chung Y-Y, Lee J-W, Kim C-H. Measuring the Impact of Femoral Head Size on Dislocation Rates Following Total Hip Arthroplasty. Hip Pelvis. 2017:29(2):91-6.

20. Kurtz SM, Lau E, Baykal D, Springer BD. Outcomes of ceramic bearings after primary total hip arthroplasty in the Medicare population. J Arthroplasty. 2017;32(3):743-9.

21. Crouse DL, Leonard PS, Boudreau J, McDonald JT. Associations between provider and hospital volumes and postoperative mortality following total hip arthroplasty in New Brunswick: results from a provincial-level cohort study. Can J Surg. 2018;61(2):88.

22. Le Cossec C, Colas S, Zureik M. Relative impact of hospital and surgeon procedure volumes on primary total hip arthroplasty revision: a nationwide cohort study in France. Arthroplasty Today. 2017;3(3):176-82.

23. Doro C, Dimick J, Wainess R, Upchurch G, Urquhart A. Hospital volume and inpatient mortality outcomes of total hip arthroplasty in the United States. J Arthroplasty. 2006:21(6):10-6.

24. Moher D, Liberati A, Tetzlaff J, Altman DG, The PG. Preferred Reporting Items for Systematic Reviews and Meta-Analyses: The PRISMA Statement. PLOS Med. 2009;6(7):e1000097.

25. Horan TC, Gaynes RP, Martone WJ, Jarvis WR, Emori TG. CDC Definitions of Nosocomial Surgical Site Infections, 1992: A Modification of CDC Definitions of Surgical Wound Infections. Infect Control Hosp Epidemiol. 1992;13(10): 606-8.

26. Moher D, Liberati A, Tetzlaff J, Altman DG. Preferred reporting items for systematic reviews and meta-analyses: the PRISMA statement. Ann Internal Med. 2009;151(4):264-9.

27. Moher D, Liberati A, Tetzlaff J, Altman DG, Group P. Preferred reporting items for systematic reviews and meta-analyses: the PRISMA statement. PLoS Med. 2009;6(7):e1000097-e.

28. Shea BJ, Reeves BC, Wells G, Thuku M, Hamel C, Moran J, et al. AMSTAR 2: a critical appraisal tool for systematic reviews that include randomised or non-randomised studies of healthcare interventions, or both. BMJ. 2017;358: j4008.

29. Katz JN, Barrett J, Mahomed NN, Baron JA, Wright RJ, Losina E. Association between hospital and surgeon procedure volume and the outcomes of total knee replacement. JBJS. 2004;86(9):1909-16. 
30. Katz JN, Phillips CB, Baron JA, Fossel AH, Mahomed NN, Barrett J, et al. Association of hospital and surgeon volume of total hip replacement with functional status and satisfaction three years following surgery. Arthritis Rheum. 2003:48(2):560-8.

31. Muilwijk J, van den Hof S, Wille JC. Associations between surgical site infection risk and hospital operation volume and surgeon operation volume among hospitals in the Dutch nosocomial infection surveillance network. Infect Control Hosp Epidemiol. 2007;28(5):557-63.

32. Pd P, Losina E, Phillips CB, Fossel AH, Mahomed N, Lingard EA, et al. Determinants of discharge destination following elective total hip replacement. Arthritis Care Res. 2004;51(6):1009-17.

33. Taylor HD, Dennis DA, Crane HS. Relationship between mortality rates and hospital patient volume for Medicare patients undergoing major orthopaedic surgery of the hip, knee, spine, and femur. J Arthroplasty. 1997; 12(3):235-42.

34. Boas R, Ensor K, Qian E, Hutzler L, Slover J, Bosco J. The relationship of hospital charges and volume to surgical site infection after total hip replacement. Am J Med Qual. 2015;30(3):283-8.

35. Katz JN, Losina E, Barrett J, Phillips CB, Mahomed NN, Lew RA, et al. Association between hospital and surgeon procedure volume and outcomes of total hip replacement in the United States Medicare population. JBJS. 2001;83(11):1622-9.

36. Kreder HJ, Deyo RA, Koepsell T, Swiontkowski MF, Kreuter W. Relationship between the volume of total hip replacements performed by providers and the rates of postoperative complications in the state of Washington. JBJS. 1997;79(4):485-94.

37. Kreder HJ, Williams JI, Jaglal S, Hu R, Axcell T, Stephen D. Are complication rates for elective primary total hip arthroplasty in Ontario related to surgeon and hospital volumes? A preliminary investigation. Can J Surg. 1998;41(6):431

38. Meyer E, Weitzel-Kage D, Sohr D, Gastmeier P. Impact of department volume on surgical site infections following arthroscopy, knee replacement or hip replacement. BMJ Qual Saf. 2011;20(12):1069-74.

39. Namba R, Inacio M, Paxton E. Risk factors associated with surgical site infection in 30491 primary total hip replacements. J Bone Joint Surg Br. 2012;94(10):1330-8.

40. Paterson JM, Williams Jl, Kreder HJ, Mahomed NN, Gunraj N, Wang X, et al. Provider volumes and early outcomes of primary total joint replacement in Ontario. Can J Surg. 2010;53(3):175

41. Kaneko T, Hirakawa K, Fushimi K. Relationship between peri-operative outcomes and hospital surgical volume of total hip arthroplasty in Japan. Health Policy. 2014;117(1):48-53.

42. SooHoo NF, Farng E, Lieberman JR, Chambers L, Zingmond DS. Factors that predict short-term complication rates after total hip arthroplasty. Clin Orthop Relat Res. 2010;468(9):2363-71.

43. Huang C-S, Cheu Y-D, Ying J, Wei M-H. Association between provider volume and comorbidity on hospital utilization and outcomes of total hip arthroplasty among National Health Insurance enrollees. J Formos Med Assoc. 2011;110(6):401-9

44. Mäkelä KT, Häkkinen U, Peltola M, Linna M, Kröger H, Remes V. The effect of hospital volume on length of stay, re-admissions, and complications of total hip arthroplasty: a population-based register analysis of 72 hospitals and 30,266 replacements. Acta Orthopaedica. 2011;82(1):20-6.

45. Martineau P, Filion KB, Huk OL, Zukor DJ, Eisenberg MJ, Antoniou J. Primary hip arthroplasty costs are greater in low-volume than in high-volume Canadian hospitals. Clin Orthop Relat Res. 2005:437:152-6.

46. Mitsuyasu S, Hagihara A, Horiguchi H, Nobutomo K. Relationship between total arthroplasty case volume and patient outcome in an acute care payment system in Japan. J Arthroplasty. 2006;21(5):656-63.

47. Shi H-Y, Chang J-K, Chiu H-C. Volume associations in total hip arthroplasty: a nationwide Taiwan population-based study. J Arthroplasty. 2013:28(10):1834-8.

48. Courtney PM, Frisch NB, Bohl DD, Della Valle CJ. Improving Value in Total Hip and Knee Arthroplasty: The Role of High Volume Hospitals. J Arthroplasty. 2018;33(1):1-5.

49. Frisch NB, Courtney PM, Darrith B, Della Valle CJ. Do higher-volume hospitals provide better value in revision hip and knee arthroplasty? Bone Joint J. 2017:99-B(12):1611-7.

50. Lavernia CJ, Guzman JF. Relationship of surgical volume to short-term mortality, morbidity, and hospital charges in arthroplasty. J Arthroplasty. 1995;10(2):133-40

51. Pamilo KJ, Peltola M, Mäkelä K, Häkkinen U, Paloneva J, Remes V. Is hospital volume associated with length of stay, re-admissions and reoperations for total hip replacement? A population-based register analysis of 78 hospitals and 54,505 replacements. Arch Orthopaedic Trauma Surg. 2013;133(12): 1747-55.

52. Ramkumar PN, Navarro SM, Frankel WC, Haeberle HS, Delanois RE, Mont MA Evidence-based thresholds for the volume and length of stay relationship in total hip arthroplasty: outcomes and economies of scale. J Arthroplasty. 2018;33(7):2031-7.

53. Styron JF, Koroukian SM, Klika AK, Barsoum WK. Patient vs provider characteristics impacting hospital lengths of stay after total knee or hip arthroplasty. J Arthroplasty. 2011;26(8):1418-26.e262.

54. Judge A, Chard J, Learmonth I, Dieppe P. The effects of surgical volumes and training centre status on outcomes following total joint replacement: analysis of the Hospital Episode Statistics for England. J Public Health (Oxf). 2006;28(2):116-24

55. de Vries LM, Sturkenboom MC, Verhaar JA, Kingma JH, Stricker BH. Complications after hip arthroplasty and the association with hospital procedure volume: a nationwide retrospective cohort study on 50,080 total hip replacements with a follow-up of 3 months after surgery. Acta Orthopaedica. 2011:82(5):545-52.

56. Cécile CM. Provider volume and short term complications after elective total hip replacement: an analysis of Belgian administrative data. Acta Orthopædica Belgica. 2011;77:311-9.

57. Glassou E, Hansen T, Mäkelä K, Havelin LI, Furnes O, Badawy M, et al. Association between hospital procedure volume and risk of revision after total hip arthroplasty: a population-based study within the Nordic Arthroplasty Register Association database. Osteoarthritis Cartilage. 2016; 24(3):419-26.

58. Dy CJ, Bozic KJ, Pan TJ, Wright TM, Padgett DE, Lyman S. Risk factors for early revision after total hip arthroplasty. Arthritis Care Res. 2014 66(6):907-15.

59. Espehaug B, Havelin LI, Engesaeter LB, Vollset SE. The effect of hospital-type and operating volume on the survival of hip replacements: a review of 39,505 primary total hip replacements reported to the Norwegian Arthroplasty Register, 1988-1996. Acta Orthopaedica Scandinavica. 1999: 70(1):12-8.

60. Khatod M, Cafri G, Namba RS, Inacio MC, Paxton EW. Risk factors for total hip arthroplasty aseptic revision. J Arthroplasty. 2014;29(7):1412-7.

61. Manley M, Ong K, Lau E, Kurtz SM. Effect of volume on total hip arthroplasty revision rates in the United States Medicare population. JBJS. 2008;90(11): 2446-51.

62. Singh JA, Kwoh CK, Boudreau RM, Lee GC, Ibrahim SA. Hospital volume and surgical outcomes after elective hip/knee arthroplasty: A risk-adjusted analysis of a large regional database. Arthritis Rheum. 2011;63(8):2531-9.

63. Maceroli MA, Nikkel LE, Mahmood B, Elfar JC. Operative mortality after arthroplasty for femoral neck fracture and hospital volume. Geriatr Orthop Surg Rehabil. 2015;6(4):239-45

64. Hughes RG, Garnick DW, Luft HS, McPhee SJ, Hunt SS. Hospital volume and patient outcomes: the case of hip fracture patients. Med Care. 1988:1057-67.

65. Solomon DH, Losina E, Baron JA, Fossel AH, Guadagnoli E, Lingard EA, et al. Contribution of hospital characteristics to the volume-outcome relationship: dislocation and infection following total hip replacement surgery. Arthritis Rheum. 2002:46(9):2436-44.

66. Sharkey PF, Shastri S, Teloken MA, Parvizi J, Hozack WJ, Rothman RH. Relationship between surgical volume and early outcomes of total hip arthroplasty: do results continue to get better? J Arthroplasty. 2004;19(6): 694-9.

67. Riley G, Lubitz J. Outcomes of surgery among the Medicare aged: surgical volume and mortality. Health Care Financ Rev. 1985;7(1):37.

68. Chien LN, Chu HF, Liu CH, Chung KP, Tsauo JY, Ng YY, et al. Association between hospital and surgeon procedure volume with outcome of total hip replacement. Taiwan J Public Health. 2003;22(2):118-26.

69. Lau RL, Perruccio AV, Gandhi R, Mahomed NN. The role of surgeon volume on patient outcome in total knee arthroplasty: a systematic review of the literature. BMC Musculoskelet Disord. 2012;13(1):250.

70. Weinheimer KT, Smuin DM, Dhawan A. Patient Outcomes as a Function of Shoulder Surgeon Volume: A Systematic Review. Arthroscopy. 2017;33(7): 1273-81.

71. Malik AT, Panni UY, Mirza MU, Tetlay M, Noordin S. The impact of surgeon volume on patient outcome in spine surgery: a systematic review. Eur Spine J. 2018;27(3):530-42. 
72. Malik AT, Panni UY, Masri BA, Noordin S. The impact of surgeon volume and hospital volume on postoperative mortality and morbidity after hip fractures: a systematic review. Int J Surg. 2018;54:316-27.

73. Muilwijk J, Walenkamp G, Voss A, Wille JC, Van den Hof S. Random effect modelling of patient-related risk factors in orthopaedic procedures: results from the Dutch nosocomial infection surveillance network 'PREZIES'. J Hosp Infect. 2006;62(3):319-26.

74. Minnema B, Vearncombe M, Augustin A, Gollish J, Simor AE. Risk factors for surgical-site infection following primary total knee arthroplasty. Infect Control Hosp Epidemiol. 2004;25(6):477-80.

75. Ong KL, Kurtz SM, Lau E, Bozic KJ, Berry DJ, Parvizi J. Prosthetic joint infection risk after total hip arthroplasty in the Medicare population. J Arthroplasty. 2009;24(6):105-9.

76. Urquhart DM, Hanna FS, Brennan SL, Wluka AE, Leder K, Cameron PA, et al. Incidence and risk factors for deep surgical site infection after primary total hip arthroplasty: a systematic review. J Arthroplasty. 2010;25(8):1216-22 e3.

77. Geubbels EL, Wille JC, Nagelkerke NJ, Vandenbroucke-Grauls CM, Grobbee DE, de Boer AS. Hospital-related determinants for surgical-site infection following hip arthroplasty. Infect Control Hosp Epidemiol. 2005;26(5):435-41.

78. Farber BF, Kaiser DL, Wenzel RP. Relation between surgical volume and incidence of postoperative wound infection. N Engl J Med. 1981;305(4):200-4.

79. Gaynes RP, Solomon S. Improving hospital-acquired infection rates: the CDC experience. Jt Comm J Qual Improv. 1996;22(7):457-67.

80. Taylor GJ, Mikell FL, Moses HW, Dove JT, Katholi RE, Malik SA, et al. Determinants of hospital charges for coronary artery bypass surgery: the economic consequences of postoperative complications. Am J Cardiol. 1990;65(5):309-13.

81. Collins TC, Daley J, Henderson WH, Khuri SF. Risk factors for prolonged length of stay after major elective surgery. Ann Surg. 1999;230(2):251-9.

82. Procter LD, Davenport DL, Bernard AC, Zwischenberger JB. General Surgical Operative Duration Is Associated with Increased Risk-Adjusted Infectious Complication Rates and Length of Hospital Stay. J Am Coll Surg. 2010; 210(1):60-5.e2

83. O'Malley NT, Fleming FJ, Gunzler DD, Messing SP, Kates SL. Factors Independently Associated With Complications and Length of Stay after Hip Arthroplasty: Analysis of the National Surgical Quality Improvement Program. J Arthroplasty. 2012;27(10):1832-7.

84. Varadarajulu S, Kilgore ML, Wilcox CM, Eloubeidi MA. Relationship among hospital ERCP volume, length of stay, and technical outcomes. Gastrointest Endosc. 2006;64(3):338-47.

85. Pasquali SK, Li JS, Burstein DS, Sheng S, O'Brien SM, Jacobs ML, et al. Association of center volume with mortality and complications in pediatric heart surgery. Pediatrics. 2012;129(2):e370.

86. Juillard C, Lashoher A, Sewell CA, Uddin S, Griffith JG, Chang DC. A national analysis of the relationship between hospital volume, academic center status, and surgical outcomes for abdominal hysterectomy done for leiomyoma. J Am Coll Surg. 2009;208(4):599-606.

87. Braga M, Ridolfi C, Balzano G, Castoldi R, Pecorelli N, Di Carlo V. Learning curve for laparoscopic distal pancreatectomy in a high-volume hospital. Updates Surg. 2012;64(3):179-83.

88. Patti MG, Corvera CU, Glasgow RE, Way LW. A hospital's annual rate of esophagectomy influences the operative mortality rate. J Gastrointest Surg. 1998;2(2):186-92.

89. Patel H, Khoury H, Girgenti D, Welner S, Yu H. Burden of surgical site infections associated with arthroplasty and the contribution of Staphylococcus aureus. Surg Infect. 2016;17(1):78-88.

90. Prevention $\mathrm{OoD}$, Promotion $\mathrm{H}$. National action plan to prevent health careassociated infections: road map to elimination. Available from:)(Accessed April 10, 2017) http://www health gov/hcq/prevent_hai asp\# CAUTI View in Article. 2015.

91. Kurtz SM, Lau E, Watson H, Schmier JK, Parvizi J. Economic burden of periprosthetic joint infection in the United States. J Arthroplasty. 2012;27(8 Suppl):61-5 e1.

92. Kurtz SM, Lau E, Schmier J, Ong KL, Zhao K, Panvizi J. Infection burden for hip and knee arthroplasty in the United States. J Arthroplasty. 2008;23(7):984-91.

93. Deficit Reduction Act of 2005, (2005).

94. Control CfD, Prevention, Statistics NCFH. Hospitalization for total hip replacement among inpatients aged 45 and over: United States, 2000-2010. 2015.

95. Katz JN, Wright EA, Wright J, Malchau H, Mahomed NN, Stedman M, et al. Twelve-year risk of revision after primary total hip replacement in the US Medicare population. J Bone Joint Surg Am Vol. 2012;94(20):1825.
96. Foundation KF. Hospital adjusted expenses per inpatient day. 2015.

97. Jolback P, Rolfson O, Mohaddes M, Nemes S, Karrholm J, Garellick G, et al. Does surgeon experience affect patient-reported outcomes 1 year after primary total hip arthroplasty? Acta Orthop. 2018;89(3):265-71.

98. Jolback P, Rolfson O, Cnudde P, Odin D, Malchau H, Lindahl H, et al. High annual surgeon volume reduces the risk of adverse events following primary total hip arthroplasty: a registry-based study of 12,100 cases in Western Sweden. Acta Orthop. 2019;90(2):153-8.

99. Aujesky D, Mor MK, Geng M, Fine MJ, Renaud B, Ibrahim SA. Hospital volume and patient outcomes in pulmonary embolism. Can Med Assoc J. 2008;178(1):27-33

100. Halm EA, Lee C, Chassin MR. Is volume related to outcome in health care? A systematic review and methodologic critique of the literature. Ann Internal Med. 2002;137(6):511-20.

101. Luft HS, Hunt SS, Maerki SC. The volume-outcome relationship: practicemakes-perfect or selective-referral patterns? Health Serv Res. 1987;22(2):157.

102. Laucis NC, Chowdhury M, Dasgupta A, Bhattacharyya T. Trend toward highvolume hospitals and the influence on complications in knee and hip arthroplasty. J Bone Joint Surg Am. 2016;98(9):707.

\section{Publisher's Note}

Springer Nature remains neutral with regard to jurisdictional claims in published maps and institutional affiliations.
Ready to submit your research? Choose BMC and benefit from:

- fast, convenient online submission

- thorough peer review by experienced researchers in your field

- rapid publication on acceptance

- support for research data, including large and complex data types

- gold Open Access which fosters wider collaboration and increased citations

- maximum visibility for your research: over $100 \mathrm{M}$ website views per year

At BMC, research is always in progress.

Learn more biomedcentral.com/submissions 